\title{
Negotiating Professional Knowledge and Responsibility in Cross-sectoral Telemedicine'
}

\section{Annette Kamp,}

Associate Professor, PhD, University of Roskilde, Denmark ${ }^{2}$

\section{Agnete Meldgaard Hansen,}

\author{
Assistant Professor, PhD, University of Roskilde, Denmark
}

\begin{abstract}
In ongoing efforts of rationalization and retrenchment in the Danish health care sector, tasks are increasingly moved from costly specialized hospital departments to the primary health care sector, where less specialized personnel take on these tasks. Telemedicine plays an important role in facilitating local access to specialized competences at central hospitals through ICT systems and establishes new virtual spaces for cross-sectoral cooperation between hospital and municipal health care workers. In an explorative ethnographic study, comprising interviews and participant observation, of telemedicine-based interaction between community nurses and specialized hospital nurses, we show how the 'tele-ulcer' system becomes a site for professional development for community nurses, although a hierarchization of professional knowledge also takes place. Furthermore, extensive articulation work is necessary to make the tele-ulcer system work. We illuminate how contradictory divisions of responsibility may result from the design of the sociotechnical system, leaving professionals to deal with risks and insecurity.
\end{abstract}

\section{KEYWORDS}

cross-sectoral cooperation / community nursing / inter-professional relations / nursing / technology / telemedicine

\section{Introduction}

ntegration and co-creation is a new mantra for reforming the health care sector in many western countries, including the Nordic countries (Magnussen et al. 2009). This may be seen as a response to the fragmentation of the health care sector that has resulted from the long line of reforms experienced in recent years. Reforms inspired by New Public Management ideas in particular, with their focus on marketization, privatization, and customer-orientation, have contributed to this fragmentation of institutions, and have made inter-professional collaboration in the health care sector more difficult (see, e.g., Bovbjerg 2011; Møller 2014). The new forms of governance are often termed New Public Governance (NPG). NPG covers ideas of networked and collaborative forms of governing, thus supporting collaboration between different levels, sectors, and actors and engaging stakeholders - public as well as private - in problem-solving and service production (Torfing \& Triantafillou 2013). Consequently, new forms of collaboration between professionals across sectors and levels are introduced.

\footnotetext{
${ }^{1}$ You can find this text and its DOI at https://tidsskrift.dk/njwls/index.

${ }^{2}$ Corresponding author: Annette Kamp email kamp@ruc.dk.
} 
In this paper, we present a study of cross-sectoral cooperation between specialists at a hospital department and community nurses in a municipality, facilitated by telemedical technology in a specific area, ulcers, which is an important and large work area within community nursing. This kind of cooperation is established as part of current endeavors of strengthening 'a near, local and integrated healthcare sector', endeavors that are prevailing in all Nordic countries (Grimsmo, Anders, \& Magnusson 2015; Grimsmo, Kirchhoff, \& Aarseth 2015; KL 2012). 'The local healthcare system' implies that health care tasks are moved from costly and specialized hospital departments to the primary health care sector, where less specialized personnel take on these tasks, while having access to specialized competences at hospitals. It is worth noting that this is part of ongoing austerity measures that are seen as an unquestionable precondition, as the quote below underlines:

With the limits to growth in public expenses, better cooperation and use of resources are needed, implying innovation and services at the lowest effective care and cost level. In the future, the near, local and integrated healthcare sector is expected to be one of the answers to the future challenges of healthcare. Subsequently, cooperation between hospitals, municipalities and health practitioners must be strengthened, and the competences of the healthcare sector must be used effectively. (Committee for the local care system 2017, p.4)

Telemedicine is considered an important tool for accomplishing these goals, as it is viewed as a means of efficient communication, supervision, and transfer of knowledge and data (KL 2012). In Denmark, telemedicine has been a prioritized focus area within welfare state policy and across government levels since 2008, which may explain why Denmark is one of the countries, where telemedicine is in widespread use in daily practice (The Government, LGDK and Danish Regions 2016). Similar uses of telemedicine can be found in other Nordic countries, although so far in more isolated and less comprehensive use (see, e.g., RiksSar 2018). In the Danish context, the term telemedicine is used broadly to describe health care services provided using information and communications technologies (ICT), through which the patient and the health professional providing the service are made independent of a physical meeting (Sundhedsdatastyrelsen 2015). In the case of tele-ulcer studied here, telemedicine is used as a means of establishing virtual spaces for cross-sectoral inter-professional cooperation concerning diagnosis, treatment, and monitoring of ulcers. Standardized information and pictures of ulcers are exchanged and plans for treatment and care are discussed and supervised through the system.

Our point of departure is that telemedicine and cross-sectoral cooperation between health care professionals should be studied contextually, in order to address the paradoxes and tensions that appear when the societal framing of telemedicine meets the cultural and organizational contexts, where specific telemedical technologies are integrated into the daily practices of health care professionals.

The majority of studies on the implications of tele-technologies for professional health care work focus on ICT-solutions used to provide care to patients at a distance (e.g., Oudshoorn 2012). They stress how virtualization may alter the character of the social contact between patients and professionals, how it may affect the observations professionals are able to make (Mol et al. 2010; Van Hout et al. 2015), and how the 
validity of the patients' own measurements and observations become a new uncertaintyfactor (Oudshoorn 2008). Studies of telemedical arrangements that are employed as means of disseminating and sharing knowledge between professionals across sectors often mainly focus on their implications for health outcomes and effectiveness of services. An exception is Trondsen (2011) who focuses on Norwegian patients' experiences of tele-ulcer. Furthermore, Nicolini (2007), in his study of telecardiology, contributes to the understanding of the impacts of such systems on working life. Drawing on insights from practice theory, he points out that telemedical cooperation is not simply about redistributing tasks and accountabilities, and shows that a reframing of knowledge, identities, and inter-professional relations is taking place.

This paper draws on an explorative ethnographic field study of the 'tele-ulcer'technology, through which community nurses in the primary health care sector discuss their treatment of patients with (chronic) ulcers with wound specialists - tele-nurses - at a specialized hospital department through an ICT-system. We analyze the practice of cross-sectoral cooperation among these different and hierarchically positioned groups of nurses via telemedicine, exploring the implications for how professional knowledge and responsibility are negotiated and how cross-sectoral professional relations are developed and sustained.

\section{Analytical approach}

With the tele-ulcer-system, a new distribution of tasks and responsibilities is introduced in the field of ulcer-care. In analyzing the implications of this sociotechnical arrangement, we combine understandings of technology-use drawn from Science and Technology Studies (STS) with insights from the sociology of professions and standardization.

Contributions from technology studies emphasize the mutual shaping of technology and actors. Technologies are interpreted and shaped, when applied in specific contexts, and may be used in innovative and unexpected ways. Likewise, engaging with technologies may also transform professional identities and social relations. This is obviously the case when looking at technologies aiming at redistributing tasks, knowledge, and responsibilities ( Halford et al. 2010; Orlikowski 2007). So, the nurses working with telemedicine must not be seen merely as 'implementers' of a pre-defined technology, which shapes their actions and abilities as health care professionals. Rather, we conceive the nurses as actively engaging in a subjective process of framing and using the tele-ulcer technology in their specific contexts and in their interactions with each other and their patients.

An equally important insight from the STS-tradition is that health care provision takes place in complex sociotechnical networks. This concept draws our attention to how health care provision is distributed across various sites, which are connected through specific care infrastructures. Care infrastructures are defined as the 'pervasive enabling resources' that allow treatment and care to travel (Bowker et al. 2009; Langstrup 2013). This insight is particularly relevant in a health care sector characterized by a complex set of weakly connected institutions and actors, private as well as public (Torfing \& Triantafillou 2013). To be workable, such infrastructures are dependent on constant and often invisible work, conceptualized as 'articulation work' (Star \& Strauss 1999).

These insights allow us to include a complex view on the sociotechnical context that telemedicine is part of and provide concepts that may grasp invisible parts of nurses' 
work. However, in order to illuminate the paradoxes, contradictions, and conflicts that may occur when aiming at redistribution of knowledge and responsibilities, we also include insights from the sociology of professions and standardization.

Here, we draw on understandings of professional knowledge and identity as dynamic entities. Thus, we conceive professional knowledge and identity as not only formed through education in the Weberian sense, emphasizing specialized, well-defined knowledge, and professional ethics, but also as reformulated and developed locally in interaction with work tasks, colleagues, and work organization (Evetts 2011; Salling Olesen et al. 2011). Thus, we perceive the transformation process we observe with the introduction of tele-ulcer as involving negotiation of forms of knowledge, identities, and responsibilities.

Knowledge-sharing through ICT often implies standardization and de-contextualization, and thus privileges certain abstract forms of professional knowledge over others (Halford et al. 2010; Kamp \& Dybbroe 2016; Timmermans \& Epstein 2010). This is of particular interest when studying nursing. As in many other welfare professions, professional knowledge in nursing is heterogeneous and encompasses abstract, specialized knowledge obtained through formal training as well as forms of practical, embodied, and context-dependent knowledge developed in interactions with patients and artefacts (Eraut 2000; Skår 2010). Furthermore, the health care field has clear hierarchies of knowledge, which privilege abstract, specialized, scientific, and medical knowledge (Norredam \& Album 2007; Currie and White, 2012; Ernst, 2016).

Distribution of responsibilities are often highly formalized in cross-sectoral work arrangements. In practice, however, responsibilities are negotiated. As, for example, Kilminster and Zukas (2013) argue, professional responsibility cannot be regarded as unequivocally placed with specific actors, and it cannot be attributed to their individual decision-making. Responsibilities are negotiated in the everyday practices of the various participants in the sociotechnical network, and must be analyzed as distributed, fluid, relational, and dynamic. Fenwick (2014) further points out that responsibilities may be conflictual referring to multiple claims on responsibility toward, for example, patients, colleagues, organizations, etc.

Against this background, our specific research questions are: How are tasks, knowledge, and responsibility negotiated in the nurses' work with tele-ulcer? Which kinds of articulation work are related to making this sociotechnical network work? Which paradoxes, contradictions, and conflicts arise in the work of tele-nurses? And how does this affect cross-sectoral professional relations?

The article is structured as follows: After a presentation of our methodology, we proceed to our analysis, which is organized in two sections, the first dealing with the negotiation of professional knowledge, and the second addressing the question of professional responsibility. In the concluding discussion, we summarize and discuss our findings and answers to the four above-mentioned research questions and relate this to our wider research framework.

\section{Methodology}

Tele-ulcer technology has been in use in all Danish municipalities (the local level) and at regional hospitals (the central level) since 2012. The fieldwork presented in this paper is explorative and was conducted in a hospital department specializing in wounds, and 
in two local areas of a large municipality, which were in contact with that particular hospital department through the tele-ulcer technology.

The tele-ulcer technology was in widespread use in the municipality and hospital department, and had been so since 2012. Both the hospital department and municipality can be considered frontrunners that have specifically prioritized this widespread use of the technology for cross-sectoral cooperation. With this choice of site for our fieldwork, we thus gained access to knowledge of telemedical practices that had moved beyond the pilot-project stage and had become an important part of daily practices. The practices we have studied are thus not representative of all uses of the tele-ulcer system in the Danish context. Rather, the knowledge presented here provides rich, in-depth insight into daily practices with tele-ulcer in a specific context where this has been given priority. Hence, we do not to present general knowledge, directly applicable across contexts, but context-dependent knowledge (Flyvbjerg 2006) that illustrates possibilities, tensions, and paradoxes related to the use of the tele-ulcer technology for cross-sectoral cooperation. Knowledge, which may resonate with and be grounds for reflection in other contexts, where the tele-ulcer system, or similar technologies, are used.

In the studied context, the use of the tele-ulcer system is organized in the following way: community tele-nurses (registered nurses working as generalists in municipal health care services) are trained in a 1-week course at the specialized hospital unit. After the training, they can communicate with hospital specialists (registered nurses specialized in wound care, supported by a doctor) concerning treatment of ulcers. They upload an assessment and photographs of ulcers in treatment every fortnight through the teleulcer ICT system. This ICT system is built around standardized categories and checklists for ulcer assessment and furthermore contains text-fields that the community nurses use, to ask for advice on treatment for instance. The specialized tele-nurses at the hospital are obliged to answer questions within 2-3 days. Apart from answering questions, they may also intervene if they disagree with given assessments, or if they need further information. The community tele-nurses decide which patients to include in the tele-ulcer system, following certain municipal guidelines; patients suffering from diabetic ulcers are always included, but patients with other types of complex ulcers, which require specialist attention, are also included.

In keeping with our understanding of health care work as taking place in complex sociotechnical networks and as distributed across a number of sites and actors, we conducted our study as a multisited ethnography (Marcus 1995). In 2016-2017, we thus conducted interviews with nurses and managers, and carried out participant observation of telemedical practices at various sites in the tele-ulcer network. An overview of the empirical material is presented in Table 1 .

Generally, we chose to observe and interview experienced practitioners in the teleulcer network (between 1 and 4 years of experience working with tele-ulcer). We did this in order to gain knowledge of the everyday use of the technology and obtain full accounts from experienced users of the technology, of how nursing practices developed in interaction with the tele-ulcer system. An exception to this is our observations from the training course for new community tele-nurses, where we gained valuable insight into the knowledge, roles, and responsibilities community nurses are expected to develop and take on to work in tele-ulcer.

Our observations were conducted mainly as shadow observations (Czarniawska 2007), where we followed the observed nurses throughout a working day at the hospital, 
Table I Overview of the empirical study

\begin{tabular}{|c|c|c|c|c|}
\hline Observations & Site & Duration & $\begin{array}{l}\text { Number of } \\
\text { professionals } \\
\text { observed }\end{array}$ & $\begin{array}{l}\text { Participant } \\
\text { characteristics }\end{array}$ \\
\hline & $\begin{array}{l}\text { Tele-care unit, } \\
\text { Hospital dept. }\end{array}$ & 2 days & 2 & $\begin{array}{l}\text { Specialized wound } \\
\text { nurses, working as tele- } \\
\text { nurses in the tele-ulcer } \\
\text { system }\end{array}$ \\
\hline & $\begin{array}{l}\text { Outpatient clinic, } \\
\text { Hospital dept. }\end{array}$ & 2 days & 2 & $\begin{array}{l}\text { Specialized wound } \\
\text { nurses working with } \\
\text { tele-ulcer patients when } \\
\text { these from time to } \\
\text { time are treated at the } \\
\text { hospital }\end{array}$ \\
\hline & $\begin{array}{l}\text { Municipal health } \\
\text { care clinics }\end{array}$ & 2 days & 2 & $\begin{array}{l}\text { Community tele-nurses } \\
\text { working in clinics }\end{array}$ \\
\hline & $\begin{array}{l}\text { Ride-along with } \\
\text { home nurses }\end{array}$ & 4 days & 4 & $\begin{array}{l}\text { Community tele-nurses } \\
\text { working in patients' } \\
\text { homes }\end{array}$ \\
\hline & $\begin{array}{l}\text { Training course for } \\
\text { new community } \\
\text { tele-nurses at the } \\
\text { hospital dept. }\end{array}$ & 3 days & 30 & $\begin{array}{l}\text { New community tele- } \\
\text { nurses, instructors from } \\
\text { the hospital dept. (doc- } \\
\text { tors, nurses, technicians) }\end{array}$ \\
\hline & $\begin{array}{l}\text { Network meeting } \\
\text { in the municipality }\end{array}$ & 2 hours & 13 & $\begin{array}{l}\text { Managing staff from the } \\
\text { hospital department, } \\
\text { municipal managers, } \\
\text { consultants and nurses }\end{array}$ \\
\hline $\begin{array}{l}\text { Individual } \\
\text { interviews }\end{array}$ & \multicolumn{3}{|l|}{ Participants } & $\begin{array}{l}\text { Number of } \\
\text { interviews }\end{array}$ \\
\hline & \multicolumn{3}{|c|}{$\begin{array}{l}\text { Community tele-nurse working in clinic } \\
\text { (also observed) }\end{array}$} & 1 \\
\hline & \multicolumn{3}{|c|}{$\begin{array}{l}\text { Community tele-nurses working in homes } \\
\text { (also observed) }\end{array}$} & 2 \\
\hline & \multicolumn{3}{|c|}{ Area manager in the municipality } & I \\
\hline & \multicolumn{3}{|c|}{ Municipal consultants } & 2 \\
\hline & \multicolumn{3}{|c|}{ Tele-nurse at hospital dept. (also observed) } & I \\
\hline \multirow[t]{3}{*}{$\begin{array}{l}\text { Group } \\
\text { interviews }\end{array}$} & \multicolumn{3}{|c|}{ Participants } & $\begin{array}{l}\text { Number of } \\
\text { interviews }\end{array}$ \\
\hline & \multicolumn{3}{|c|}{$\begin{array}{l}\text { Tele-ulcer management at hosp. department, } \\
\text { two nurses, one doctor }\end{array}$} & 1 \\
\hline & \multicolumn{3}{|c|}{$\begin{array}{l}\text { One community nurse-consultant and one } \\
\text { community } \\
\text { tele-nurse working in clinic (also observed) }\end{array}$} & I \\
\hline
\end{tabular}


in local clinics, or in patients' homes. In these observations, as well as at the training course and network meeting we observed, we took on the role of 'partly participating observers' (Fangen 2010), meaning that we did not participate directly in work activities, but engaged in normal interaction with both professionals and patients and had informal conversations with them throughout these days. All observations were documented through notes taken when appropriate, and elaborated from memory shortly after (DeWalt \& DeWalt 2010).

Our interviews followed semi-structured interview guides. In the interviews with nurses (lasting 30-50 minutes), we focused on the experience of working with teleulcer in terms of professionalism, professional development, and cross-sectoral cooperation, communication, and responsibility. Our interviews with managers and consultants (lasting 60-90 minutes) focused on the overall aims of the tele-ulcer cooperation, and on organizational matters, thus providing essential background knowledge. All interviews were conducted in Danish, recorded, and later transcribed. Quotes have been translated into English by the authors. All persons interviewed and observed have given their consent to participation and have been anonymized in the following (alternative names and nondisclosure of easily identifiable characteristics). The research was conducted in accordance with the Danish code of conduct for research integrity (Ministry of higher education and science 2014).

In preparation for the analyses presented below, the two authors systematically read the empirical material several times, focusing on themes of professional knowledge, responsibility, and articulation work in relation to tele-ulcer. On the basis of these readings and continuous discussions, the main arguments of the analysis were developed and structured, as an 'analytical re-description' of the empirical material inspired by the conceptual framework presented above (Phillips \& Jørgensen 2002; Stormhøj 2006). The quotes and descriptions of observed interactions presented in the analysis have been selected as illustrative examples of broader tendencies in the empirical material. Following this process, we presented our findings at two meetings with, respectively, representatives of the hospital department and of one of the local areas of the municipality. At these meetings, participants could comment on and discuss the findings, providing useful feedback and deepening our understanding of their practices.

\section{Analysis}

Our analysis is presented in two main sections. In the first section, we show how professional knowledge is negotiated in relation to the tele-ulcer technology, and the second section focuses on how professional responsibility is negotiated and extended.

\section{Negotiating legitimate professional knowledge}

In this first section of our analysis, we analyze how the tele-ulcer-technology brings questions of professional knowledge into play and leads to both a professionalization welcomed by the community nurses and to struggles over the legitimacy of different types of professional nursing knowledge. 
The introduction of tele-ulcer-technology entails the training of community nurses in the specialized medical field of ulcer healing and treatment, and the medical terminology connected to this. Specialized terminology forms the basis for the design of the tele-ulcer IT system that conveys standardized, abstract information on ulcers and their development, and is presented as the common language that makes cross-sectoral collaboration succeed. Our observations showed that establishing this common language is an explicit goal of the short training course, which community nurses attend in order to become registered tele-nurses with access to the ICT-system.

The community nurses generally perceive this new position with access to supervision and specialized knowledge as a development toward more qualified and autonomous work, and receive this development with great enthusiasm. As community nurses, they work mostly on their own (in small local clinics or patients' homes), and have often found themselves in difficult situations when having to make decisions on the treatment of complex ulcers.

An illustration of this general experience is provided in our interview with Maud, a nurse at a local health care clinic. She explains how this new access to specialists enables her to get professional feedback both in specific cases and more generally, and she remarks: 'This has been a very big professional step forwards'. She also observes how her own professionalism is transformed by being involved with the tele-ulcer collaboration: 'Little by little your way of thinking changes, you start thinking like them [the specialist nurses], right?'

However, this development may also imply that the practical and context-sensitive knowledge that is the cornerstone of community nurses' work with their patients is subordinated and silenced. In our study, we observed examples of struggles over knowledge in the field, struggles that in some cases strain the cross-sectoral relations between the community nurses, and nurses at the specialized hospital department.

One of the home nurses, Susan, underlines this experience when, in a conversation after one of the researchers accompanied her on patient-visits in the district, she says the following:

It is as if they have the truth, and they raise their finger and point out when they find that we and others in the municipality do not do the right thing. But of course, it is easy for them to come up with an easy and correct solution; they adhere to the pure, the abstract principles. But for us, facing realities, it is not at all certain that this [the ideal solution] is going to work (Susan, home nurse).

One of the issues at stake is how to bandage ulcers. All the community nurses emphasize how important it is to have knowledge of the everyday life of the patients, their habits, their activities, and how they move about.

Stina, another community nurse, remarks eagerly:

They [the tele-nurses at the hospital department] think there is a best way of bandaging. But there is not. You have to consider that the patients have a life, so you have to make compromises. I have often seen how a bandage, though perfect, loosens and slides down when the patient moves about (Stina, nurse at a municipal healthcare clinic).

Later the same day, one of the researchers observes Stina, who is in the local clinic bandaging the finger of a patient with a diabetic ulcer. She explains how she tries to adjust 
the way she bandages the patient in special ways, to take into account that he works as a cleaning assistant, wet work that impedes the healing of the ulcer. He ought to take sick-leave while he heals but cannot do so for financial reasons.

During our shadow observations, Rita, a home nurse, gives another example. She points out how many patients do not like to wear orthopedic sandals in winter - the correct choice of footwear from a professional point of view. They find that sandals look odd and make you stick out from other people in cold weather. Therefore, Rita normally engages in finding other solutions for them, like buying normal shoes and trying to fit them for the diabetic foot.

So, as illustrated above, community nurses have to make compromises between the right treatment according to the abstract knowledge and the solutions that work in practice considering the behavior, lifestyle, and quality of life of the patient. Thus, intimate knowledge of the patient and his/her everyday life - the type of practical and context-sensitive knowledge highlighted by Skår (2010) and Eraut (2000) as integral to professional practice - is central to community nursing.

Furthermore, knowledge of the patient is not only important in the treatment of an ulcer, but it also plays an important role in the assessment of ulcers. In one of our group interviews, two of the community nurses explained that assessing ulcers is normally about observing, touching, and testing (e.g., for infection), activities connected to the specific ulcer, which can easily be reported in a standardized manner in the tele-ulcer system and thereafter assessed at a distance by the specialized tele-nurses at the hospital. However, they emphasized, it is also important to take notice of small signs concerning the patients' general well-being, things that appear in conversations with the patient, when you know him or her very well - for example, bad sleep or pains. These small signs may make you suspect that something else is wrong, and that the condition is more complex than assumed while making a standard assessment. Again, contextual professional knowledge is crucial.

\section{Like a detective}

From the above analysis, it might appear that the specialized tele-nurses at the hospital are immersed in the medical paradigm on ulcer treatment, and do not recognize the context- and experience-based knowledge of the community nurses. However, the situation is more complex, and in order to understand the process where different forms of knowledge are at stake, the interplay between technology and nurses - the sociotechnical network - must be considered.

Our shadow-observations revealed that the work as a specialized tele-nurse at the hospital has a quite different character than community nursing in clinics and homes. Their work consists of ICT-based administrative case management, and here they have no direct contact with the patients. However, these specialists have a high level of competence in wound care obtained through work at the hospital's wound ward and outpatient clinic, as they work in rotation between these departments and tele-ulcer. In this work, they have attained a general knowledge of the types of patients and wounds treated in home nursing, and in some cases, they also have knowledge of specific patients treated in the tele-ulcer system. Thus, they have a good basis for cooperating with and advising the community nurses in the municipality. 
Our observations and interviews with the hospital nurses revealed an extensive knowledge of some of the individual patients included in the tele-ulcer system - especially of long-term patients with chronic or semi-chronic ulcers. This knowledge is utilized in their assessments and feedback to the community nurses. In their accounts of their work, they describe their way of working 'like a detective' as the most meaningful and fulfilling part of their work. The work of the detective is, according to the nurses, to puzzle together the sparse pieces of information about patients and ulcers provided by the ICT system in order to find out what causes the problems with healing specific ulcers, and to find creative solutions. So, this could be considered a kind of articulation work, work that is required in consequence of the distributed nature of work. As Anna, a tele-nurse at the hospital explained in our interview:

The thing about being a detective is this: sometimes you get very little information. And then you must try to assemble the big picture.... try to find out what it is, what it is about. Without being able to see the patient. Then seek to solve the problem as well as possible, uncover what is going on here. Not being able to see the patient is an extra challenge, but you must guess. From signs: Where is the ulcer situated? How about the shoes? Information you may collect from files and pictures, and then you may ask the community nurses further questions in order to unravel it. (Anna, specialized tele-nurse)

In her description of working as a detective, Anna describes some of the difficulties of conducting diagnosis and treatment at a distance often described in the literature on tele-technologies in nursing (Oudshoorn 2008). Nevertheless, she finds this work of synthesizing information from a complex assemblage of different representations of the patient and his/her ulcer (Allen 2014) challenging and rewarding. As Nicolini (2007) also observes in his study of cardiac specialists working at a distance, the professionals do not only seek a representation but also an emotional and sensuous understanding of the patient and the ulcer. In our conversations with Anna and her colleague, while observing their work, it was clear that they often created vivid mental images of the patients and their contexts, from the cues and signs found in the tele-ulcer system, and used these in their assessments and feedback to the community nurses.

However, performing the role of a detective may often conflict with austerity measures and the temporal rationalization of the nurses' work. Our observations revealed that the specialized nurses have to go through around 50 patient-cases per day. Time consumption per case varies considerably - some cases take 2 minutes to process, others 20; but there is a great focus on processing as many cases as possible, getting through the long list of tasks and questions waiting in the tele-ulcer system. In addition to answering specific questions, this 'case handling work' is also a matter of ensuring quality and providing additional information in the cases. Therefore, the specialist nurses experience a heavy workload and have to work quickly in order to comply with the response time (2-3 working days) that is settled in the agreement between the municipalities and hospital.

The ICT technology is designed in a way that supports this kind of rapid workflow. Its architecture allows for conveying simple standardized characterizations of the ulcers, relevant measurements (e.g., pulse and infection numbers), supplemented by pictures that give a visual impression of the ulcer and its development over time. Contextual knowledge may be communicated in free text fields and comments, but the specialized nurses are not presented with this knowledge automatically when they enter the system 
- they have to go looking for it actively and try to piece the information together for a fuller picture. So, the mediation of knowledge that takes place through the tele-ulcer technology's design with standardized forms and checklists, foregrounds, and privileges abstract decontextualized knowledge (Timmermans \& Epstein 2010; see also Kamp \& Dybbroe 2016), often leaving contextual knowledge out of the synthesis carried out by the specialist nurses.

As Anna explains in our interview:

If it is not written in the right field [a note on allergic reactions], then we might write: This looks fine, but I think you should use another kind of bandage, a foam bandage. Then they [the community nurses] write back: But really, we wrote last time that the patient gets eczema when foam bandages are applied. Alright, it is possible that you wrote that, but you did not write it in the right place, and then we cannot guess that. We are not backtracking, reading everything that has been written on every patient; we have 500 of them. (Anna, specialized telenurse)

In this case - an allergic reaction - information is actually supposed to appear automatically among the standardized information, but it may be lost if it is written in a free text field. Much contextual information on the patients' everyday life and conditions can only be written in free text fields and will be difficult and time consuming to trace.

The hierarchization of abstract de-contextualized knowledge of ulcers in general over their contextualized knowledge of individual patients cannot be conceived as simply rooted in opposition between two groups of nurses. The specialists and the community nurses both utilize the two forms of knowledge, though to a different extent. Rather, a complex interplay between the design of the tele-ulcer interface and the heavy workload and fast pace at the telemedicine office results in this privileging of abstract, de-contextualized knowledge. Furthermore, the hierarchization of knowledge is also embedded in the basic organizational setup of the cross-sectoral cooperation, where community nurses seek advice from specialized hospital nurses. This setup contributes to strengthening already existing professional hierarchies in the health care sector, where highly specialized knowledge and professions are attributed high prestige (Norredam \& Album 2007).

The above analysis illustrates how a hierarchization of professional knowledge is institutionalized in the configuration of the sociotechnical network that facilitates geographically distributed care for ulcer patients. The specific interplay of the tele-ulcer ICT system's interface, the fast work pace and heavy workload in the telemedicine office, and the organizational setup of the cross-sectoral cooperation, all interact to privilege communication through abstract, decontextualized concepts. In some cases, this evokes struggles between the involved professional groups, over what is conceived as legitimate knowledge. While all the community nurses clearly acknowledge and highly value their improved access to abstract medical knowledge on ulcers, we also see examples of struggle for recognition of their practice and the contextually bound knowledge that is crucial for this.

\section{Extending and negotiating professional responsibility}

As described above, the tele-ulcer network implies access to supervision and specialized knowledge and thus offers the community nurses a new position. However, as we will 
discuss in the following section, the tele-ulcer technology may also be used in ways that bring professionalism and responsibility in play in unexpected manners.

First, the sociotechnical network provides the community nurses with new possibilities for exerting autonomy in their work.

The community nurses use their access to the tele-ulcer technology as a new means of managing their patients' journey through a fragmented health care system. In order to promote their recovery, they act as 'case managers' for their patients - taking on a coordinating role. This type of 'trajectory mobilization' is an important element of nursing work that is often overlooked both by formal work descriptions, scientific literature, and even by nurses themselves (Allen 2014). Allen has described this form of work as an example of 'articulation work' (Star \& Strauss 1999) - as it is work carried out to 'support trajectories of care by connecting network actors together' (Allen 2014). In this manner, nurses work to bind the health care system together.

The task of healing ulcers is distributed between different sites (public hospitals, doctors' consultancies, municipal nursing clinics, private sector foot therapist clinics, private homes) and actors (various professionals, patients, and relatives), and connected by infrastructures like ICT, control visits, medicine cards, etc. in a complex geography of care (Langstrup 2013). Coordinating for their patients in such geographies of care has long been something that all the community nurses practice. As Rita explains in our interview:

For some of them [the patients with multiple diseases] it is really difficult to make it all come together. They are going through six different procedures, for example, at three different hospitals and must try to make it work. They have to order transport to all these visits, and they cannot remember, and the wife cannot remember either. So, you just have to support them in whatever they need help for, in order to make their daily life work. (Rita, home nurse)

The tele-ulcer network provides them with new access points to other parts of the health care system, which can help them realize this trajectory mobilization in new ways. For example, the community nurses can use the sociotechnical network related to the teleulcer system to coordinate for patients with complex problems. They may use the connections they have gained through the use of the system to help patients find out when they have an appointment for surgery in other parts of the hospital system, or help them make such an appointment.

Another important feature of being part of the sociotechnical network is the possibilities to include and exclude actors. Time and timeliness is extremely important to the process of healing ulcers, so the pace of the patients' journey through the health care system is an important point of intervention for the community nurses. So, in observations and interviews with the community nurses, they underlined how the tele-ulcer system enabled them to by-pass the patients' general practitioners, who are normally gatekeepers for admissions to hospital. General practitioners, the community nurses underline in our conversations, are not specialized in ulcers, and do not know how to proceed. Often, they ask the community nurses what to do in these cases and then time passes, and treatment is delayed.

By including patients in the tele-ulcer system, the nurses may ensure patients' access to a specialized hospital unit, and the formal responsibility for the treatment of the ulcer 
will be placed with a doctor at the hospital, rather than with the general practitioner. Visiting the hospital's specialized outpatient clinic is the starting point for the tele-ulcer process, and this is followed by regular (though infrequent) visits.

Furthermore, our observations and interviews showed that some of the community nurses also use the tele-ulcer network to secure the patients' access to resources that are crucial for the healing of their ulcers - for example, special (costly) medical bandages and treatment from foot therapists (who trim dead tissue in wounds to enhance healing). By sending them to the hospital's outpatient clinic, this may be achieved quickly and with less coordination efforts. This is a way of bypassing municipal authorities that cannot grant costly bandages, or of bypassing private-practice foot therapists, who complicate the coordination task. As Maud explains in our interview, this simplifies the process: 'they [the outpatient clinic] have it all in one place, 'the whole package' is provided in there'.

So, we see two types of trajectory mobilization, which give high priority to nurses' accountability toward the patients and their recovery, and which in the latter case downplay organizational accountabilities. This work of trajectory mobilization may be seen as a way of extending the community nurses' professional responsibility and autonomy in practice (Kilminster \& Zukas 2013). The nurses are with their new points of access and connections in the health care system able to provide more efficient trajectories and more specialized care. In this light, their efforts may be seen as a form of exertion of responsible autonomy (Trist \& Bamforth 1951), as they not only use the possibilities and discretion provided for them through the tele-ulcer network to extend their influence on healing processes but also to extend their responsibility for patients' trajectories beyond their formal work descriptions.

New technological systems may, as described by, for example, Nicolini (2007), introduce breaches and gaps in the chains of accountability in the health care system. In this case, on the contrary, the system offers the community nurses the possibility to remedy existing gaps and create more coherence in a fragmented health care sector.

The sociotechnical network of tele-ulcer thus in many situations allows the community nurses to expand their responsibility for the patients' treatment. In this way, they step into the general practitioners' domain, although discretely, not confronting the general practitioners with their more marginal position in this sociotechnical network. This is an innovative use of the tele-ulcer technology, which actually counteracts the political and administrative rationales for using the tele-care solution. Instead of working to decrease the flow of patients to the hospital department, thus reducing the costs of ulcer-care, the community nurses use their direct access to the hospital to increase the quality of ulcer-care and send all the patients they find necessary. In this light, the community nurses' actions may be seen as a form of (conscious or unconscious) 'responsible subversion' (Hutchinson 1990; Kirchhoff \& Karlsson 2013) of the retrenchment rationales underlying the use of telemedicine in the health care sector.

\section{Whose responsibility?}

This expansion of responsibility on the community nurses' part is not the only negotiation of professional responsibility taking place in the network. As described in the 
Introduction, the implementation of the tele-ulcer technology aims at redistributing responsibility between the central and the local level of the health care system. In this section, we show how this redistribution is not fixed, but rather fluid and negotiated in the interaction between the specialist nurses and community nurses, and we explore how this influences cross-sectoral relations.

The distribution of tasks and accountabilities are formalized and agreed upon by the two parties in a cooperation agreement. However, both types of nurses experience that the other party places new tasks and responsibilities on their shoulders in unforeseen ways. The specialized nurses point out how they are overwhelmed by the number of new updates on the tele-ulcer cases. Sometimes, they explained during our observations, the community nurses update their cases too often, and - according to the specialist nurses - ask questions that they actually should be able to answer themselves. This puts a strain on the cross-sectoral relationship, as Anna explains in an interview:

They [the community nurses] seemingly adhere to the fact that we have the ultimate responsibility for the treatment, so they ask us, even when making very small adjustments. And we think: why don't you just do it?, we wonder ... and think: what would they have done if the patient was not on tele-ulcer?

She continues:

It is also that it is so easy: 'I have a kind of hotline, so why not ask?' It is as if this is their personal 'footbook', where they just update everything. Just like on facebook ... There are some who have that tendency. ... but of course there are the experienced ulcer-nurses, and then there are the tele-nurses who have only had the one-week course. Perhaps we sometimes expect more from them than they are able to do? And ... we must allow for questions - even dumb questions - we have to allow for questions, otherwise you cannot learn. (Anna specialist nurse)

So, in the specialists' view, the establishment of the tele-ulcer network may imply that community nurses actually take advantage of the specialists being there, so that they avoid taking responsibility for decisions themselves. Also, as they reflected upon during our observations, the easy access that the technology offers may play a role in this. The specialist nurses do however also need to nurture the relations to community nurses, their partners in the cross-sectoral cooperation, and try to manage their emotions with reference to their superior role as trainers in this set-up.

In our observations and interviews, some of the community nurses, on the other hand, complain that they often feel that they are kept waiting for answers, or that these do not always sufficiently reply to their questions. Furthermore, being part of the sociotechnical network of tele-ulcer also sometimes implies a limitation of certain possibilities for the community nurses. The support from tele-nurses at the specialized hospital unit is not available in situations of acute need, for example, in cases where the condition of the patient suddenly deteriorates. Questions are answered within 2-3 working days. So, in acute cases, the patient's general practitioner must be contacted.

This puts the community nurses in a difficult situation. The general practitioners are very difficult to reach by telephone, and the nurses, as explained above, have their doubts whether these doctors will act adequately and efficiently to solve the problem. As 
Rita explains in an interview, these situations can become frustrating, and she finds that responsibility in these cases is shifted onto the community nurses' shoulders:

The problem, I think, is when something urgent happens, and we find that they [the specialized nurses] need to get involved (...) then it seems they can stretch it a bit longer. Because they know that we are there and that we keep an eye on things, and it can be sort of difficult to (...) take action when there is an acute deterioration [of a patient's condition]. (Rita, home nurse)

In situations like these, the community nurses explained that they will normally try to bypass the general practitioners and the procedure of primarily written communication of the tele-ulcer system, by trying to telephone the tele-nurses in the specialized unit. However, the hours where the specialized nurses can be reached by telephone are limited, and consequently, this strategy is not always successful. This leaves the community nurses with the responsibility to act. On the one hand, they are not formally accountable for this situation, as the responsibility for treatment is ultimately placed with doctors at the hospital department and the general practitioner. On the other hand, in practice, this responsibility lies with them and their professional ethics dictate that they should manage it one way or another, even if their course of action might be unsatisfactory and frustrating.

To summarize, the tele-ulcer network sustains intersectoral cooperation and division of tasks and responsibilities, but not in a clear-cut matter that may be described and settled unambiguously in a cooperation agreement. Responsibilities are fluid and constantly negotiated in the daily practices of the involved nurses. Dynamics of inclusion and exclusion from the network, and unpredictable shifts in workflow and temporalities in the cooperation are important in understanding the paradoxical outcomes, leading both to greater autonomy and ethical strain on the part of the community nurses, and sometimes to strained relations between the two groups of nurses.

\section{Concluding discussion}

In this paper, we have explored the implications of new forms of technology-assisted, cross-sectoral professional cooperation. Our study focuses on a specific context, the work with tele-ulcer shared by specialized hospital nurses and community nurses, an arrangement that results from recent reforms in the health care sector concerned with moving tasks to the 'lowest effective cost level'.

The tele-ulcer system provides the standardized format of communication that can make these heterogeneous contexts work together over distance (Timmermans \& Epstein 2010). Our analysis shows how the redistribution of knowledge, tasks, and responsibilities that is implied is indeed a complex and pluridirectional process. Making the tele-ulcer collaboration work requires articulation work from the nurses and involves negotiation of power and professional identity.

On the one hand, our analysis points out how a hierarchization of knowledge is at stake in the tele-ulcer collaboration. In a complex interplay between the design of the tele-ulcer-ICT-system and interface, a heavy workload and time pressure at the hospital department, and the organizational setup of the cross-sectoral cooperation, the community nurses' contextual and practical knowledge of their individual patients' 
everyday lives and conditions becomes invisible and subordinate to an abstract, standardized knowledge of ulcers in general. As scholars in the sociology of standardization (Timmermans \& Epstein 2010) highlight, standards and standardization create new languages, which make some elements of the reality of professional practice clearly visible, while other elements become difficult to represent. In the field of tele-ulcer, this type of standardization of professional language and communication contributes to a further valorization of medical, abstract knowledge (see also Kamp \& Dybbroe 2016). This leads to instances of struggle for recognition of contextual knowledge, considered crucial for community nurses' work and identities.

On the other hand, our analysis also shows how working in the tele-ulcer network enriches the work of community nurses. Through their work with telecare, they gain access to a more specialized language concerning ulcers and develop their knowledge and skills in terms of analyzing and treating complex ulcers. They experience this as a positive contribution to their professional identity, as they feel more professional and qualified in their work. Thus we do not, as in other studies of telemedicine (e.g., Nicolini 2006), find an unequivocal strengthening of existing centers of power with the introduction of telemedicine in health care networks, rather we see that certain (abstract) regimes of professional knowledge are strengthened across sectors, and a tendency toward transformation of local knowledge and professionalism in this direction.

Furthermore, making the tele-ulcer network work requires extensive articulation work from both groups of nurses, work that largely goes unnoticed in formal work plans. We encountered two different types of articulation work. At the central level, articulation work primarily takes place as a recontextualization of the standardized knowledge the specialized nurses receive through the system. When time allows, the hospital nurses work 'like detectives' to synthesize and make sense of the decontextualized fragments of information on patients and their ulcers provided through the tele-ulcer system. They work to create viable mental images of the patient and his/her context, and, as has also been described in studies of telecare practices (Nicolini 2007; Oudshoorn 2008; Pols 2011), they utilize signs and cues delivered through the ICT-system to replace the sensuous, bodily impressions, and the biographical narratives, accessible in face-to-face clinical encounters with patients.

The other type of articulation work, encountered at the local level, has a different character. With inspiration from Davina Allen (2014), this work can be described as a form of trajectory mobilization. Community nurses use the access and contacts gained through the tele-ulcer network to promote more coherent and timely treatment trajectories for their patients in a fragmented and geographically distributed health care system. Where other researchers have shown how telemedicine may introduce breaches and gaps in the chains of accountability in health care systems (Nicolini 2007), the articulation work done by the community nurses in tele-ulcer actually contributes to bridging gaps in the health care system. These practices are in line with the previously described NPGinspired efforts of creating closer links and collaboration between sectors, for example, through telemedical technology. However, it is important to underline that the bridging of sectors does not arise automatically from the implementation of the tele-ulcer system, it is dependent on nurses' articulation work. Furthermore, this articulation work has unpredicted outcomes, which do not necessarily correlate with policymakers' intentions.

The work of trajectory mobilization may be seen as an extension of community nurses' professional responsibility. It involves inclusion, bypassing, and exclusion of 
different actors in the network, and implies undertaking new professional roles, contributing to the transformation of professional identities and work practices in the field. The work of trajectory mobilization may be considered a practice of responsible autonomy (Trist \& Bamforth 1951), as community nurses use their increased space for action to improve the quality of treatment for patients. However, it may also be seen as a form of misbehavior or responsible subversion (Ackroyd \& Thompson 1999; Hutchinson 1990; Kirchhoff \& Karlsson 2013), as their actions contradict the retrenchment-rationales underpinning the implementation of the tele-ulcer system. They actually increase patients' access to costly hospital resources with the aim of increasing the quality of treatment. The community nurses thus put their responsibility toward the patients over their responsibility to follow organizational and management goals of retrenchment.

Furthermore, the (re)distribution of responsibility in the network requires constant attention. As we show, professional responsibility is not simply redistributed along clearcut lines as laid out in formal cooperation agreements. Working with the technology (re) shapes the professionals and their work-practices in the two contexts in particular ways and leads to specific tensions and hierarchies in inter-professional relations. Responsibility in the tele-ulcer network is fluid and negotiated in practice, and both groups of nurses have experiences of responsibility being shifted onto their shoulders. The study illustrates how paradoxical and contradictory divisions of responsibility may result, due to the design of the sociotechnical system, leaving professionals to deal with risks and insecurity.

Our study thus highlights the complexities and unexpected outcomes of technologically mediated cross-sectoral cooperation between professional groups in the health care system. These insights may contribute to reflection among policy makers concerned with moving health care tasks to 'the lowest efficient cost level'. Professional tasks, knowledge, and responsibilities cannot just be transferred from one level of the health care system (hospitals) to another, cheaper, level (municipalities), by way of a simple technological fix. Cooperation through telemedical-solutions does not in itself create the desired post-NPM, less expensive, and 'near, local and integrated' health care sector. Instead of understanding cross-sectoral cooperation through telemedicine as a question of a simple one-directional transfer of knowledge, tasks, and responsibilities, it seems more accurate to understand it as a number of unpredictable and pluri-directional processes of recontextualization and transformation of professional knowledge, tasks, and responsibilities. Such processes require articulation work from the involved professionals and attention to the fluid character of professional responsibility, circumstances that must be taken into account in the expectations and planning of technologically mediated cross-sectoral cooperation.

Cross-sectoral collaboration supported by telemedical technologies is a central feature of the contemporary development of the public sector in the Nordic countries and has particularly great momentum in the health care sector. The study we have presented here is explorative, based on a relatively small sample, and limited to one local context of technologically mediated cross-sectoral cooperation. As such, it raises a number of questions for further and more extensive research on changing sociotechnical networks and their implications for, for example, meaning and identity in work, interprofessional relations and hierarchies, and for the negotiation of new insecurities and responsibilities. Furthermore, research is also needed on the implications for professionals of working with telemedicine in the current societal context characterized by complex and often 
contradictory aims of austerity, quality, and empowerment of users, a context that shapes the way sociotechnical networks operate.

\section{Acknowledgments}

The research presented in this paper was funded by the Working Environment Research Fund.

\section{References}

Ackroyd, S., \& Thompson, P. (1999). Organizational Misbehavior, London: SAGE Publications Ltd. (UK). doi: http://dx.doi.org/10.4135/9781446222232.

Allen, D. (2014) 'Re-conceptualising holism in the contemporary nursing mandate: From individual to organisational relationships', Social Science \& Medicine 119: 131-138. doi: http://dx.doi.org/10.1016/J.SOCSCIMED.2014.08.036.

Bovbjerg, K. M. (2011). Motivation og mismod [Motivation and despondency], 1. edition. K. M. Bovbjerg (ed.), Aarhus: Aarhus Universitetsforlag.

Bowker, G. C., et al. (2009). 'Toward Information Infrastructure Studies: Ways of Knowing in a Networked Environment', in International Handbook of Internet Research, Dordrecht: Springer Netherlands: 97-117. doi: http://dx.doi.org/10.1007/978-1-4020-9789-8 5.

Committee for the Local Near and Integrated Health Sector (2017). Afrapportering [Report]. Copenhagen: LGDK, Danish Regions \& The State.

Currie, G., \& White, L. (2012). 'Inter-professional Barriers and Knowledge Brokering in an Organizational Context: The Case of Healthcare', Organization Studies 33(10): 1333-1361. doi: http://dx.doi.org/10.1177/0170840612457617.

Czarniawska, B. (2007). Shadowing, and Other Techniques for Doing Fieldwork in Modern Societies, Copenhagen: Copenhagen Business School Press.

DeWalt, K. M., \& DeWalt, B. R. (2010). 'Writing field notes', in Musante, K. (ed.) Participant Observation: A Guide for Fieldworkers, Lanham: AltaMira Press, pp. 138-155.

Eraut, M. (2000). 'Non-formal learning and tacit knowledge in professional work', British Journal of Educational Psychology 70(1): 113-136. doi: http://dx.doi.org/10.1348/ 000709900158001.

Ernst, J. (2016). 'Evidence-based nursing in the IED: from caring to curing?', Nordic Journal of Working Life Studies 6(1): 47. doi: http://dx.doi.org/10.19154/njwls.v6i1.4885.

Evetts, J. (2011). 'Sociological analysis of professionalism: past, present and future', Comparative Sociology 10(1): 1-37. doi: http://dx.doi.org/10.1163/156913310X522633.

Fangen, K. (2010). Deltagende observasjon [Participant Observation]. 2. edition, Bergen: Fagbokforlaget.

Fenwick, T. (2014). 'Rethinking professional responsibility: matters of account', in Fenwick, T. J. and Nerland, M. (eds) Reconceptualising Professional Learning: Sociomaterial Knowledges, Practices, and Responsibilities, Lon: Routledge: 157-170.

Flyvbjerg, B. (2006). 'Five misunderstandings about case study research', Qualitative Inquiry 12(2): 219-245. doi: http://dx.doi.org/10.1177/1077800405284363.

Grimsmo, A., Kirchhoff, R., \& Aarseth, T. (2015). 'Samhandlingsreformen i Norge [Interaction reform in Norway]', Nordiske Organisasjonsstudier 17(3): 3-12.

Grimsmo, A., \& Magnusson, J. (2015). Norsk samhandlingsreform i et internasjonalt perspektiv perspektiv [Norwegian interaction reform in an international perspective]. EVASAM, Norwegian Research Council. 
Halford, S., Obstfelder, A., \& Lotherington, A.-T. (2010). 'Changing the record: the interprofessional, subjective and embodied effects of electronic patient records', New Technology, Work and Employment 25(3): 210-222. doi: http://dx.doi.org/10.1111/ j.1468-005X.2010.00249.x.

Hutchinson, S. (1990). 'Responsible subversion: a study of rule-bending among nurses', Scholarly Inquiry for Nursing Practice 4(1): 3-17.

Kamp, A., \& Dybbroe, B. (2016). 'Struggles of professionalism and emotional labour in standardized mental health care', Nordic Journal of Working Life Studies 6(February): 67-86. doi: http://dx.doi.org/10.19154/njwls.v6i1.4886.

Kilminster, S., \& Zukas, M. (2013). 'Responsibility matters: putting illness back into the picture', Journal of Workplace Learning 25(6): 383-393. doi: http://dx.doi.org/10.1108/ JWL-08-2012-0058.

Kirchhoff, J. W., \& Karlsson, J. C. (2013). 'Expansion of output: organizational misbehaviour in public enterprises', Economic and Industrial Democracy 34(1): 107-122. doi: http:// dx.doi.org/https://doi-org.ep.fjernadgang.kb.dk/10.1177/0143831X12439113.

KL (2012). 'Det nære sundhedsvæsen [The local healthcare system]', Kommunernes Landsforening.

Langstrup, H. (2013). 'Chronic care infrastructures and the home', Sociology of Health \& Illness 35(7):1008-1022. doi: http://dx.doi.org/10.1111/1467-9566.12013.

Magnussen, J., et al. (2009). Nordic Health Care Systems : Recent Reforms and Current Policy Challenges, Maidenfield: Open University Press.

Marcus, G. E. (1995). 'Ethnography in/of the world system: the emergence of multi-sited ethnography', Annual Review of Anthropology 24:95-117. doi: http://dx.doi.org/10.1146/ annurev.anthro.24.1.95.

Ministry of Higher Education and Science (2014). Danish Code of Conduct for Research Integrity. Copenhagen: Ministry of Higher Education and Science.

Mol, A., Moser, I., \& Pols, J. (2010). Care in Practice, On Tinkering in Clinics, Homes and Farms, Mol, A., Moser, I., \& Pols, J (eds.). Bielefeld: Transcipt.

Møller, J. L., et al. (2014). 'Omsorg på markedsvilkår. Arbejdsvilkår og orienteringer i den fragmenterede danske hjemmepleje [Care on market terms. Working conditions and orientations in fragmented Danish homecare]', Tidsskrift for Arbejdsliv 16(4): 85-102.

Møller, J. L. et al. (2014). 'Omsorg på markedsvilkår - arbejdsvilkår og orienteringer i den fragmenterede danske hjemmepleje’, Tidskrift for arbejdsliv (4):85-102.

Nicolini, D. (2006). 'The work to make telemedicine work: A social and articulative view', Social Science \& Medicine 62:2754-2767. doi: http://dx.doi.org/10.1016/j.socscimed. 2005.11.001.

Nicolini, D. (2007). 'Stretching out and expanding work practices in time and space: The case of telemedicine', Human Relations 60(6): 889-920. doi: http://dx.doi.org/10.1177/ 0018726707080080.

Norredam, M., \& Album, D. (2007). 'Prestige and its significance for medical specialties and diseases', Scandinavian Journal of Public Health 35(6):655-661. doi: http://dx.doi.org/ https://doi-org.ep.fjernadgang.kb.dk/10.1080/14034940701362137.

Orlikowski, W. J. (2007). 'Sociomaterial practices: exploring technology at work', Organization Studies 28(9):1435-1448. doi: http://dx.doi.org/10.1177/0170840607081138.

Oudshoorn, N. (2008). 'Diagnosis at a distance: the invisible work of patients and healthcare professionals in cardiac telemonitoring technology' Sociology of Health \& Illness 30(2):272-288. doi: http://dx.doi.org/10.1111/j.1467-9566.2007.01032.x.

Oudshoorn, N. (2012). 'How places matter: Telecare technologies and the changing spatial dimensions of healthcare', Social Studies of Science. doi: http://dx.doi.org/10.1177/ 0306312711431817. 
Phillips, L., \& Jørgensen, M. W. (2002). Discourse Analysis as Theory and Method, London: Sage.

Pols, J. (2011). 'Wonderful webcams: about active gazes and invisible technologies', Science, Technology, \& Human Values 36(4):451-473. doi: http://dx.doi.org/10.1177/ 0162243910366134.

RiksSår (no date). RiksSårs Ehälso-projekt söker testdeltagare! [RiksSår’s E-health project is looking for test-participants!]. Available at: https:/www.yourvismawebsite.com/landstinget-blekinge/news/rikssars-ehalso-projekt-soker-testdeltagare?tm $=($ Accessed May 14, 2018).

Salling Olesen, H., Nicoll, K., \& Jütte, W. (2011). 'Editorial: professionalisation - the struggle within', European Journal for Research on the Education and Learning of Adults 2(1):7-20. doi: http://dx.doi.org/10.3384/rela.2000-7426.relae2.

Skår, R. (2010). 'Knowledge use in nursing practice: the importance of practical understanding and personal involvement', Nurse Education Today 30(2):132-136. doi: http://dx. doi.org/10.1016/J.NEDT.2009.06.012.

Star, S. L., \& Strauss, A. (1999). 'Layers of silence, arenas of voice: the ecology of visible and invisible work', Computer Supported Cooperative Work (CSCW) 8(1-2):9-30. doi: http://dx.doi.org/10.1023/A:1008651105359.

Stormhøj, C. (2006). Poststrukturalismer: videnskabsteori, analysestrategi, kritik [Poststructuralisms: theory of science, analytical strategi and critique], Frederiksberg: Samfundslitteratur.

Sundhedsdatastyrelsen (2015). NBS Telemedicinbegreber- Rapport vedrørende udarbejdelse af begrebssystem og definitioner [NBS Telemedicine concepts - Report concerning preparation of concept-system and definitions]. Copenhagen: Sundhedsdatastyrelsen.

The Government, LGDK and Danish Regions (2016). Et stærkere og mere trygt digitalt samfund. Den fællesoffentlige digitaliseringsstrategi 2016-2020 [A stronger and safer digital society. The common public sector digitalisation strategy 2016-2020].

Timmermans, S., \& Epstein, S. (2010). 'A world of standards but not a standard world: toward a sociology of standards and standardization', Annual Review of Sociology 36: 69-89. doi: http://dx.doi.org/10.1146/annurev.soc.012809.102629.

Torfing, J., \& Triantafillou, P. (2013). 'What's in a name? Grasping new public governance as a political-administrative system', International Review of Public Administration 18(2): 9-25. doi: http://dx.doi.org/10.1080/12294659.2013.10805250.

Trist, E. L., \& Bamforth, K. W. (1951). 'Some social and psychological consequences of the Longwall method of coal-getting', Human Relations 4(1):3-38. doi: http://dx.doi. org/10.1177/001872675100400101.

Trondsen, M. V (2011). 'Managing everyday life: a qualitative study of patients' experiences of a web-based ulcer record for home-based treatment', Healthcare 2:492-504. doi: http://dx.doi.org/10.3390/healthcare2040492.

Van Hout, A., Pols, J., \& Willems, D. (2015). 'Shining trinkets and unkempt gardens: on the materiality of care', Sociology of Health and Illness. doi: http://dx.doi.org/10.1111/14679566.12302. 